\title{
Notice bio-bibliographique de Miguel Palacios
}

\author{
Isabelle Reck
}

\section{OpenEdition}

Journals

Édition électronique

URL : https://journals.openedition.org/cher/402

DOI : 10.4000/cher.402

ISSN : 2803-5992

\section{Éditeur}

Presses universitaires de Strasbourg

\section{Édition imprimée}

Date de publication : 19 novembre 2020

Pagination : 163-165

ISBN : 979-10-344-0071-3

ISSN : 1968-035X

Référence électronique

Isabelle Reck, « Notice bio-bibliographique de Miguel Palacios », reCHERches [En ligne], 25 | 2020, mis en ligne le 01 octobre 2021, consulté le 20 novembre 2021. URL : http://journals.openedition.org/cher/ 402 ; DOI : https://doi.org/10.4000/cher.402 


\title{
Notice bio-bibliographique de Miguel Palacios
}

\author{
ISABELLE RECK
}

\begin{abstract}
$\mathrm{M}$ iguel Palacios (1970), auteur, metteur en scène, directeur de compagnie, et, actuellement, professeur à la ESAD de Séville (Escuela Superior de Arte Dramático) est l'un des membres de la génération «Miguel Romero Esteo », du nom du prix théâtral récompensant les textes des jeunes auteurs andalous. Trois de ses pièces ont été récompensées par ce prix: La puerta, los cuervos, la tostadora, los cuernos y el bufón cabezón cara de melón (Mention spéciale du jury en 1997), La perversa encarnación de Lilo el lila (finaliste en 1998), et El hombre del Saco (accessit 1999). Et deux autres, La Pecera et La huida l'ont été, respectivement, en 1998, par Muestras de Jóvenes Creadores Ciudad de Malaga 98 et Premios Cánovas 98, et, en 2018, par XX Certamen de teatro mínimo Rafael Guerrero.

Miguel Palacios a commencé par s'intéresser au théâtre expérimental et a intégré, à Malaga, la compagnie Teatro del Vacío. Entre 2000 et 2004, il a occupé plusieurs postes d'enseignant de langue, littérature et culture espagnole et latino-américaine (Université catholique de Lille, EDHEC Business School du Pas-de-Calais et Sciences-Po Lille). Il a créé dans le même temps un laboratoire théâtral, Théâtre Zéro ${ }^{1}$, dans la ligne droite de ce qu'il avait commencé à élaborer à Malaga. À son retour à Málaga, en 2009, il créait la compagnie Teatro Línea 6 et Teatro de los Orígenes Laboratorio. Miguel Palacios a ainsi mis en scène avec Teatro Línea 6 ses textes Muñecos (1996) en mars 2011 et El paraíso terrenal (1999) en 2013, et lesdeux "pièces pour bébés», Anamakanda et Cheshire, respectivement en février et octobre 2014. En février 2013, c'est Juan Alberto Salvatierra, membre de cette même génération, qui portait à la scène, toujours avec la même compagnie, une autre des pièces de Miguel Palacios, La reunión écrite en 2005.
\end{abstract}

1 Voir à ce propos Miguel Palacios, «Influence de la recherche et des arts plastiques dans les activités de Théâtre Zéro", dans Danetis, D. Pratiques artistiques, pratiques de recherche, Paris, l'Harmattan, 2007, p. 273-286. 
Citons parmi ses textes portés à la scène par d'autres compagnies et metteurs en scène andalous: Maruja, asesina de mosquitos, ratas, torturadores y verdugos (1995) par Efímera Teatro (Cordoue) en février 2018, dans une mise en scène de Carlos Alonso Callero; Mascarada de San Demonio mártir y la vieja pelleja Micaela (El cóctel de los demonios) (1995), par Salamandra Teatro (Malaga), en octobre 1996, dans une mise en scène de Curro Garijo Belda; El hombre del saco (1999), par Factoría Zulú (Malaga), en août 2000, dans une mise en scène de José Antonio Sedeño; et la pièce pour enfants Los grandes enigmas del Universo según la pepona Marillena (2010), traduite en anglais et représentée aussi dans cette langue sous le titre The big mysteries of the Universe, dans une mise en scène d'Antonia Gómez (2014).

Son écriture dramatique relève tant de l'écriture d'auteur que de l'écriture de plateau. Miguel Palacios est un touche-à-tout du théâtre et de l'écriture et a exploré les formes les plus radicalement postdramatiques et expérimentales. Au milieu de cette hétérogénéité des formes, il a privilégié avant tout la poésie (pour lui «le théâtre est une poésie tridimensionnelle $»^{2}$ ) et l'esthétique grotesque (notamment dans ses "tragédies délirantes») ou plutôt le néo-grotesque (ses modèles allant de Shakespeare à Beckett, Arrabal et Romero Esteo ${ }^{3}$ ), et le pop art dans ses dernières productions. Par exemple, dans sa dernière pièce (2020), El maravilloso viaje a la frontera del fin del mundo de dos hombres corrientes vestidos de superhéroes, qui met en scène deux migrants, un Maghrébin et un Africain subsaharien, à la dérive sur une bouée de plage en forme de licorne, dans les eaux «mythiques» du détroit de Gibraltar (même si le Détroit n'est pas explicitement nommé). Cette tragédie poignante, "délirante» et «dérivante», met ainsi en scène deux migrants condamnés à une mort certaine, engagés dans un dialogue très beckettien dans un "paysage" très pop-art, où le Détroit de Gibraltar se peuple de ready-made néo-baroques produits par notre civilisation de la consommation à outrance: monstres-carcasses métalliques, artéfacts flottants faits de bouteilles de plastique, autrement dit... l'art le plus contemporain flottant à la dérive sur les eaux de la mort, qui furent celles de l'Odyssée et de la belle et envoûtante Calypso, fille d'Atlas qui veille, aux portes de l'Europe et de l'Afrique, sur les deux colonnes d'Hercule.

Miguel Palacios, très attaché au dialogue des arts sur la scène ${ }^{4}$, a créé aussi, entre autres, des spectacles de "théâtre-danse» et des performances. Citons parmi ces spectacles: les deux spectacles (mise en scène et chorégraphie de Thomé Araujo, compagnie DanzaTeatro de Malaga), Los amantes del miedo en

2 Carmen Arribas, "Panorámica teatral y rasgos significativos de Miguel Palacios», reCHERches (Strasbourg, PUS), n 22, 2019, p. 89-104, p. 89.

3 Nous renvoyons au texte de Miguel Palacios publié dans ce volume, intitulé «Avantpropos. Ne me comprenez pas de travers ", où il présente et analyse ses influences majeures.

4 Voir l'article de Miguel Palacios déjà cité, «Influence de la recherche et des arts plastiques dans les activités de Théâtre Zéro», op. cit. 
avril 1995 et Tatuaje en août 1998; El paraíso de los necios, 2017 (co-écrit avec Fernando Hurtado), représenté par la Cía Danza de Fernando Hurtado.

Parmi ses pièces relevant de l'écriture de plateau et de la performance citons: La pecera (Teatro del Vacío, Malaga, septembre 1997), La retórica del azul (Fundación Godot, Malaga, mai 1997), Pequeño estudio para un retrato (1998)(Teatro del Vacío, Rome juin 1999), Trastos (Teatro del Vacío, Malaga, mars 1999), Action 0.1. Le Chicon (Théâtre Zéro, Lille, mai 2006), Action 0.3. La file de Dionysos (Théâtre Zéro, Roubaix, mars 2007), PH 8 (Les liturgies du déjeuner) (Teatro de los Orígenes Laboratorio, Festival d'Avignon OFF, juillet 2011), PH 12 (Ritual de lo visible y lo invisible) (Teatro de los Orígenes Laboratorio, Festival de Teatro Contemporáneo "El Quirófano", Malaga, 2012), Konstante 01 (Teatro de los Orígenes Laboratorio, Malaga, mars 2013) [Réécriture de El príncipe constante, de Pedro Calderón de la Barca].

Miguel Palacios expérimente et explore par ailleurs les formes théâtrales en fonction des différents publics. C'est ainsi qu'il a écrit du «théâtre pour la famille», du «théâtre pour enfants » et du «théâtre pour bébés». Et il est l'auteur d'un roman de science-fiction (Los adoradores de la serpiente roja, 2014), genre qu'il affectionne particulièrement et dont nous trouvons l'empreinte dans beaucoup de ses pièces. Ce qui n'a pas lieu d'étonner dans un théâtre «aussi engagé, politiquement, socialement et humainement, que le sien», comme le signale Carmen Arribas ${ }^{5}$, occupé à réfléchir, entre utopies et dystopies, à l'avenir de notre monde.

\section{Bibliographie}

Sélection de textes publiés

El maravilloso viaje a la frontera del fin del mundo de dos hombres corrientes vestidos de superhéroes, dans Destierro, Sevilla, Atopía, 2020.

El paraíso terrenal. AR.es, Revista de Investigación Teatral de la ESAD de Córdoba, $\mathrm{n}^{\circ} 0$, octobre 2018, p. 88-89.

Europa Light, Sevilla, Centro de Documentación de las Artes Escénicas de Andalucía (edition digitale), 2015.

La decepción del pequeño Julius Mannetari. Contraluz, Revista de Investigación Teatral de ESAD de Málaga, n 5, février 2011, p. 254-265.

Los adoradores de la serpiente roja (roman), Girona, Luces de Gálibo, 2014.

5 Carmen Arribas, op. cit., p. 89. 